\title{
The antioxidant activity of date seed: preliminary results of a preclinical in vivo study
}

\author{
Fatima Al-Meqbaali', Hosam Habib', Aws Othman², Saeda Al-Marzooqi' ${ }^{3}$, \\ Alia Al-Bawardi ${ }^{3}$, Javed Yasin Pathan ${ }^{4}$, Serene Hilary ${ }^{1}$, Usama Souka ${ }^{1}$, Suleiman Al-Hammadi², \\ Wissam Ibrahim ${ }^{1}$, Carine Platat ${ }^{1 *}$ \\ ${ }^{1}$ Nutrition \& Health Department, College of Food \& Agriculture, UAE University (UAEU), Al Ain, ${ }^{2}$ Department of Pediatrics, College of Medicine \\ \& Health Sciences, UAE University (UAEU), Al Ain, ${ }^{3}$ Department of Pathology, College of Medicine \& Health Sciences, UAE University \\ (UAEU), Al Ain, ${ }^{4}$ Department of Internal Medicine, College of Medicine \& Health Sciences, UAE University (UAEU), AI Ain
}

\section{A B S T R A C T}

\begin{abstract}
Chronic diseases (diabetes, cardiovascular diseases and cancer), are by far the leading causes of mortality and morbidity worldwide. Oxidative stress is one of the underlying mechanism in the development and enhancement of chronic diseases. Polyphenols are particularly abundant in date seeds and can contribute in the progress of chronic diseases due to antioxidant properties. The present work studies the effects of date seeds and examines the oxidative stress status on serum and organs of Male Wistar rats after feeding them with basal diet comprising 0, 2, 4 or $8 \mathrm{~g} / \mathrm{kg}$ date seed powder (DSP) for a period of 13 weeks. Isonitrogenous and isocaloric diets were subjected to all the four groups. Antioxidant status, protein and lipid oxidative biomarkers were measured in the serum and organs and histopathology was done. The results showed that DSP suggestively $(P<0.05)$ elevated the antioxidant defense system of the serum and organs. DSP decreased protein and lipid oxidative damages in the liver, muscle and brain. In addition, DSP did not alter the organs' function based on the analysis of biochemical markers. The results indicate that oxidative stress-related diseases could be possibly prevented by the DSP bioactive antioxidants.
\end{abstract}

Keywords: Antioxidant; Chronic diseases; Date seed powder; Oxidative damages; Polyphenols

\section{INTRODUCTION}

Chronic diseases (diabetes, cardiovascular disease and diabetes) contribute to $60 \%$ of all deaths in the world (WHO report, 2014). Worryingly, their global prevalence is still increasing worldwide, creating a heavy economic burden for societies (WHO report, 2003). It is well-known that nutrition is a major modifiable contributing factor to these diseases. Diet modifications have strong effects on health throughout life (WHO report, 2003). They may not only influence current health but may determine whether or not an individual will develop chronic diseases much later in life. The benefit of consuming particular food products, such as fruits and vegetables, has largely been emphasized. There is strong scientific evidence in favour of a constructive affiliation between the intake of food mainly vegetables and fruits and the possible risk factors for the development of diabetes, cardiovascular diseases and cancer (Liu, 2003). Their high content in diverse phytochemicals, including polyphenols, was suggested to explain this, at least in part (Rahman et al., 2006).

Polyphenols are secondary metabolites which are naturally found in plant products. They contribute to the colour, flavour, odour, bitterness and astringency of food. They are classified into different groups, with main groups including the flavonoids, lignans, phenolic acids and stilbenes (Pandey and Rizvi, 2009). Polyphenols may protect the cell components against oxidative damage due to oxidative stress conditions through the action of free radical scavengers (Pandey and Rizvi, 2009).

Numerous mechanisms are contributing in chronic disease development, with oxidative stress has the prime highlight (Mayne, 2003). It occurs when there is imbalance between the oxygen and nitrogen species (ROS/RNS) and the antioxidant system. ROS, including nitric oxide, superoxide, hydrochlorous acid, hydrogen peroxide, peroxynitrite

\footnotetext{
*Corresponding author:

Carine Platat, Nutrition \& Health Department, College of Food \& Agriculture, United Arab Emirates University, PO Box 15551, Al Ain, United Arab Emirates. Tel: +971 3 7136558. Fax: +971 3 7136902. E-mail: platatcarine@uaeu.ac.ae
} 
and hydroxyl radical are considered prime factors in cell stimulation and signalling pathways as a response to either intra- or extracellular environmental factors. Nonetheless, the overproduction of ROS can damage lipids, proteins, and even alter the DNA, along with inhibiting biological functions. Ultimately, this can add to the progress of major chronic diseases (Khansari et al., 2009; Uttara et al., 2009).

Lipids, especially polyunsaturated fatty acids, are more likely to be oxidized. Polyunsaturated fatty acid oxidation results in Malondialdehyde (MDA) which is the key lipid peroxidation biomarker (Ho et al., 2013). Proteins are also prone to be oxidized by ROS, leading to the formation of cross-linkages between protein molecules followed by protein fragmentation via oxidation of the protein backbone (Chevion et al., 2000). Protein carbonyl is the most important protein oxidation marker so far (Beal 2002; Chevion et al., 2000; Berlett and Stadtman, 1997). Protein carbonyls accumulation has been detected in numerous human diseases, including diabetes, inflammatory bowel disease (IBD), Alzheimer's disease (AD), Parkinson's disease, essential hypertension, cystic fibrosis, ulcerative colitis and arthritis (Dalle-Donne et al., 2003).

If oxidative stress contributes to the physiological changes that lead to chronic diseases and aging, it is reasonable to assume that antioxidant compounds will have a significant contribution in the prevention and/or treatment of these disorders. Therefore, free radical scavengers, which are polyphenols lower the risk of nutrition-related chronic diseases by playing a significant role in prevention and repair of cellular damage (Bouayed and Bohn, 2010).

Interestingly, the date seed, a wasted by-product of the date fruit, which is very popular in the Middle East, has been associated with favourable nutritional properties among which a high polyphenol content (Habib and Ibrahim, 2011b; Hamada et al., 2002). Indeed, besides the high amounts of diverse vitamins, minerals and fibres, date seeds were recognized as one of the greatest plant sources of polyphenols, greater than popular sources of polyphenols like grape or flaxseeds (Habib et al., 2014). Ultra-high-performance liquid chromatography-diode array detection-electrospray ionisation-mass spectrometry (UPLC-DAD-ESI-MS) analyses estimated the content of polyphenols of date seeds to be close to $51 \mathrm{~g} / \mathrm{kg}$. Flavan3-ols, including proanthocyanidins, were showed to be the main class in date seeds with $46.800 \mathrm{~g} / \mathrm{kg}$ of epicatechin and $3.380 \mathrm{~g} / \mathrm{kg}$ of catechin. Among polyphenols, catechin and epicatechin were identified as the polyphenols with the highest principal pro-health effects (Habib et al., 2014).

Antioxidant capacities particularly of catechins and proanthocyanidins have been intensely studied and have been shown to demonstrate a scavenging activity for various form of free radicals including hydroxyl group $(\mathrm{OH})$, superoxide anion $(\mathrm{O} \cdot 2-)$, Nitric oxide $(\mathrm{NO})$ and alkyl peroxyl radicals (Jeong and Kong, 2004). Also catechins have the ability to modulate the enzymes that generate these free radicals such as $\mathrm{iNOS}$ and $\mathrm{XO}$ to reduce oxidative stress (Velayutham et al., 2008). Furthermore, in other studies, catechins have been shown to reduce lipid peroxidation (MDA) and elevates endogenous antioxidant such as glutathione (Simos et al., 2012). Date seeds polyphenols antioxidant properties have already been demonstrated in vitro (Habib, et al., 2014; Platat et al., 2014; Shams-Ardekani et al., 2010).

The studies conducted in animals confirmed this antioxidant effect of date seeds, in addition to other benefits on animal growth and recovery in cases of hepatotoxicity (Al-Farsi and Lee, 2011; Al-Qarawi et al., 2004; Ali et al., 1999). One study conducted in male Wistar rats revealed that after a 30-day period of feeding with a diet comprising 0,70 or $140 \mathrm{~g} / \mathrm{kg}$ date seeds, a reduction of liver and serum malondialdehyde (MDA) was shown (Habib and Ibrahim, 2011a). Consequently, this provides evidence of the beneficial effect of date seeds, making date seeds a strong candidate as a functional food product to prevent and/or treat major chronic diseases. However, studies on the potential of date seed powder on oxidative damage in organs other than the liver are lacking. Additionally, in most animal studies, the main biochemical markers were considered, but tissues were rarely observed. Besides, the studies that has been conducted so far are short term studies, so long term studies (3 months) are deficient. Furthermore, the DSP doses used in this study are not too high as compared to those used in other studies, and could be normally consumed by humans with a normal diet.

Therefore, the present study was performed to determine the effect of date seed powder on oxidative damage and antioxidant status in different organs, including the liver, heart, brain and muscle. In addition, the absence of negative impact on organs functions and blood lipid profile was explored.

\section{MATERIALS AND METHODS}

\section{Diets and feeding regimen Date seeds}

Date seeds of the Khalas variety were attained from $\mathrm{Al}$ Ain Dates Factory (Al Ain, UAE). The season (summer) of collecting tamr (fully ripe dates) is usually spread over a period of 2-3 months. Samples were collected randomly from tamr batches at the end of the season, with no preference for size, colour, appearance or firmness. The seeds were first soaked in water, washed to remove any adhering date flesh, air-dried, and ground into coarse 
powder using a hammer mill (Platat et al., 2015). Table 1. Depicts the chemical composition of the date seeds from Khalas variety. The methods used for the chemical analysis of the date seeds have been described previously (Habib and Ibrahim, 2011b, Platat et al., 2015). The antioxidant content and capacity of date seeds from Khalas variety was also described previously in Habib and Ibrahim (2011a).

\section{Animals}

The protocol used in this study was reviewed by the Animal Research Ethics Committee, College of Medicine and Health Sciences, United Arab Emirates University, $\mathrm{Al}$ Ain and was conducted according to the principles of the Declaration of Helsinki (Platat et al., 2015). It was recorded as protocol number A19-12 and was approved on June 4, 2012. The study was conducted in accordance with the "Guide for the Care and Use of Laboratory Animals" (1985). Normal 6-week-old male Wistar rats (43-113 g) were obtained from the College of Medicine and Health Sciences Animal Facility, UAE University, Al Ain. The rats were housed in plastic cages under controlled conditions of 12 -h light $/ 12$-h dark cycle, $50 \%$ humidity and $25 \pm 3^{\circ} \mathrm{C}$ (Platat et al., 2015).

\section{Experimental design}

The animals were divided into four groups. They were fed for 13 weeks before sacrifice. The experimental

Table 1: Chemical composition of date seeds

\begin{tabular}{lc}
\hline Component & Amount $\mathbf{g} / \mathbf{k g}$ \\
\hline Moisture & 88.00 \\
Protein & 58.00 \\
Fat & 79.00 \\
Ash & 10.00 \\
Total dietary fiber & 729.00 \\
Carbohydrate & 36.00 \\
Polyphenols & 51.00 \\
Epicatechin & 46.80 \\
Catechin & 3.38 \\
\hline
\end{tabular}

diet was prepared by Dyets Inc. (Bethlehem, PA, USA). An isocaloric and isonitrogenous basal diet, similar to the American Institute of Nutrition AIN-93G purified rodent diet, was used. Three date seed powder diets, DSP1, DSP2 and DSP3, were prepared by using $2 \mathrm{~g} / \mathrm{kg}, 4 \mathrm{~g} / \mathrm{kg}$ and $8 \mathrm{~g} / \mathrm{kg}$ DSP in the diet, respectively. Table 2. illustrates the details about the composition of the experimental diets. During the experimental period, the control group (5 rats) received the basal diet, and the DSP1, DSP2 and DSP3 groups (9 rats each) received the DSP1, DSP2 and DSP3 diets, respectively. Water and feed were provided ad libitum to the rats and there were no gavage feeding. Food was weighed every day to estimate the food intake of the animals as shown in Table 3. The doses for the rats were determined based on (1) the recommended quantity of carbohydrates for adults $(210 \mathrm{~g} /$ day), (2) the average food intake of rats (25 g/day), according to data from a previous study (Habib and Ibrahim, 2011a), and (3) the initial animal weight (43-113 g).

\section{Preparation of serum, plasma, tissue fragments and homogenate}

The rats were sacrificed at the end of the experimental period after overnight fasting. They were anaesthetized with pentobarbital and killed following blood withdrawal via heart puncture. Blood samples were drawn into dry (to obtain serum) and heparinized (to obtain whole blood) tubes. Portions of serum were immediately separated after centrifuging the blood sample and used to measure the levels of glucose, total cholesterol and HDL, total protein, albumin, urea, creatinine, creatine kinase (CK), aspartate aminotransferase (AST), alanine aminotransferase (ALT), alkaline phosphatase (ALP), gamma-glutamyl transpeptidase (GGT), vitamin C, the lipid peroxidation product malondialdehyde (MDA) and protein-bound carbonyls (Platat et al., 2015).

Liver, muscle, heart and brain tissues were removed, blotted and weighed, and $200 \mathrm{~g} / \mathrm{kg}$ homogenate was prepared in

Table 2: Composition of experimental diets

\begin{tabular}{|c|c|c|c|c|c|}
\hline Ingredient $\mathbf{g} / \mathbf{k g}$ & $\begin{array}{c}\text { Purified AIN-93M rodent } \\
\text { diet }(\mathrm{g} / \mathrm{kg})\end{array}$ & Control (g/kg) & $\begin{array}{l}0.2 \% \text { date seeds } \\
\text { powder ( } \mathrm{g} / \mathrm{kg} \text { food) }\end{array}$ & $\begin{array}{l}0.4 \% \text { date seeds } \\
\text { powder ( } \mathrm{g} / \mathrm{kg} \text { food) }\end{array}$ & $\begin{array}{l}0.8 \% \text { date seeds } \\
\text { powder ( } \mathrm{g} / \mathrm{kg} \text { food) }\end{array}$ \\
\hline Casein & 140.00 & 140.00 & 139.88 & 139.77 & 139.54 \\
\hline Dextrose & 155.00 & 155.00 & 155.00 & 155.00 & 155.00 \\
\hline Corn starch & 465.69 & 465.69 & 465.69 & 465.69 & 465.69 \\
\hline Sucrose & 100.00 & 100.00 & 99.93 & 99.86 & 99.71 \\
\hline Cellulose & 50.00 & 50.00 & 48.54 & 47.08 & 44.17 \\
\hline Corn oil & 40.00 & 40.00 & 39.84 & 39.68 & 39.37 \\
\hline t-Butylhydroquinone & 0.008 & 0.008 & 0.008 & 0.008 & 0.008 \\
\hline Salt mix \#210050 & 35.00 & 35.00 & 35.00 & 35.00 & 35.00 \\
\hline Vitamine mix \#310025 & 10.00 & 10.00 & 10.00 & 10.00 & 10.00 \\
\hline L-Cystine & 1.80 & 1.80 & 1.80 & 1.80 & 1.80 \\
\hline Choline bitartrate & 2.50 & 2.50 & 2.50 & 2.50 & 2.50 \\
\hline Date seeds powder & & & 2.00 & 4.00 & 8.00 \\
\hline
\end{tabular}




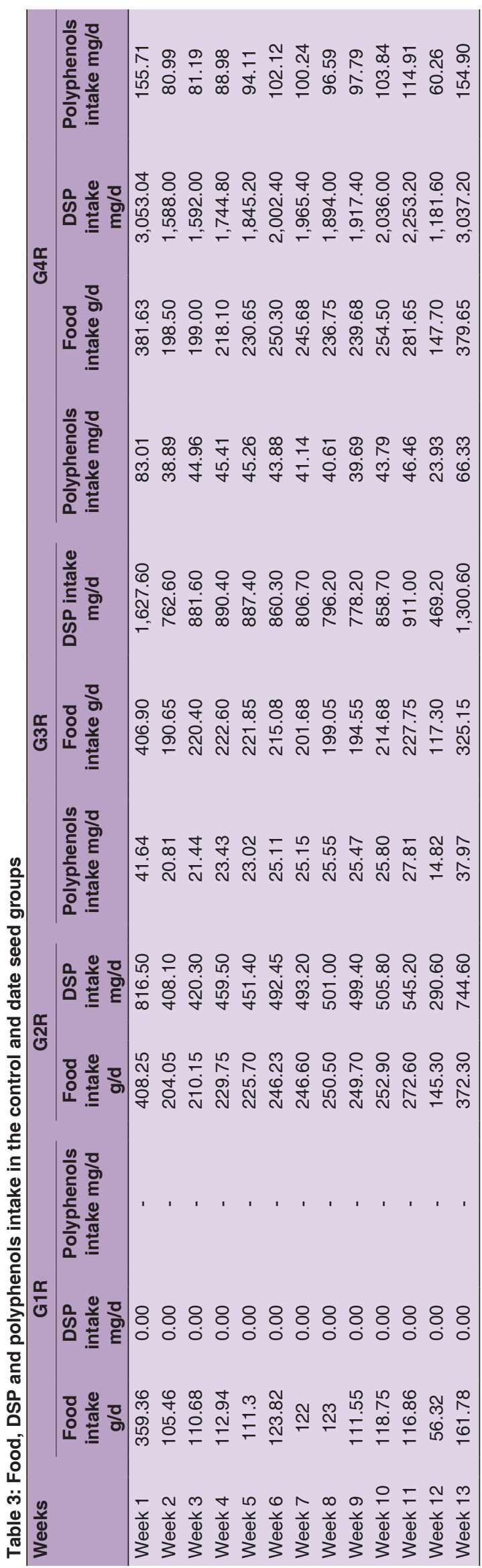

ice-cold $15.5 \mathrm{~g} / \mathrm{L} \mathrm{KCl}$ in $0.05 \mathrm{~mol} / \mathrm{L}$ Tris buffer (pH 7.4) using a homogenizer. Portions of the organ homogenate were processed to measure the levels of protein, vitamin C, vitamin E, glutathione (GSH), MDA and protein-bound carbonyls.

\section{Biochemical parameters}

Glucose, total cholesterol, HDL, urea, creatinine, CK, AST, ALT, ALP and GGT were measured in serum using enzymatic colorimetric methods on Roche/Hitachi Cobas c systems (Integra 400 Plus, Germany). Total protein content was measured in blood and organs following the methods of Lowry et al. (Lowry et al., 1951).

\section{Antioxidant status biomarkers}

Vitamin C concentration was measured using the methods described by Omaye et al. (1979), after reaction with 2,4-dinitrophenylhydrazine at $520 \mathrm{~nm}$. Vitamin E was measured by HPLC using a fluorescence detector with excitation at $205 \mathrm{~nm}$ and emission at $340 \mathrm{~nm}$ (Hatam and Kayden, 1979).

Glutathione was measured spectrophotometrically at $412 \mathrm{~nm}$ after reaction with dithionitrobenzoic acid (Sedlak and Lindsay, 1968).

The method described by Re et al. (1999) was used to measure ABTS. Sample volume was adapted. Fresh ABTS was prepared for each assay. Serum sample $(1 \mathrm{ml})$ were allowed to react with $1 \mathrm{ml}$ of the ABTS solution and the absorbance was taken at $734 \mathrm{~nm}$ after 7 min using a spectrophotometer. The percentage inhibition calculated as ABTS radical scavenging activity:

$(\%)=[($ Abs control - Abs sample $) /($ Abs control $)] \times 100$

where Abs control is the absorbance of ABTS radical in phosphate buffer saline PH 7.4; Abs sample is the absorbance of ABTS radical solution mixed with the serum sample.

\section{Oxidative damage biomarkers MDA}

Lipid peroxidation product MDA was measured using the modified procedure of $\mathrm{Li}$ and Chow (1994). The reaction mixture was extracted with isobutanol and the fluorescence intensity was measured at $515 \mathrm{~nm}$ and emission at $550 \mathrm{~nm}$ using a spectrofluorometer. 1,1,3,3Tetramethoxypropane was used as a standard.

\section{Protein-bound carbonyls}

The extent of protein oxidation, was determined spectrophotometrically at $530 \mathrm{~nm}$ by the 2,4-dinitrophenylhydrazine method described by (Levine et al., 1990). 


\section{Histopathology}

Following the procurement of organs, tissue fragments were placed in 10\% buffered formalin for 8 hours. Manual tissue processing involved dehydration using ethyl alcohol, clearing using xylene and infiltration by paraffin. Fourmicrometre sections were obtained from paraffin blocks and stained with haematoxylin and eosin. Fragments of the liver, muscle, heart and brain were prepared.

\section{Statistical analysis}

Statistical analysis was performed using SPSS for Windows (Version 23; SPSS Inc. Chicago, Illinois, USA). The means \pm standard error (s.e.) were calculated for each group and each parameter in serum and in each organ. The significance $(\mathrm{P}<0.05)$ of variance was determined. Posthoc Tukey's tests were used to compare the results between DSP1, DSP2, DSP3 and control groups in serum and in each organ.

\section{RESULTS}

\section{Growth of rats}

The growth rate in the different groups is presented in Table 4. The results showed that there was no significant weight change over the 13 weeks. The average body weight gain at the end of the feeding period was $307.8 \pm 19.57 \mathrm{~g}$ for the control group, $343.80 \pm 14.99 \mathrm{~g}$ for DSP1 group, $354.25 \pm 17.31 \mathrm{~g}$ for DSP2 group and $341.20 \pm 10.83 \mathrm{~g}$ for DSP3 group.

\section{Biochemical parameters}

Biochemical parameters in the different groups are shown in Table 4. Glucose, cholesterol, HDL-C, total serum protein, and albumin were not significantly different between groups. In contrast, CK, which is a biomarker of high levels of tissue damage, were higher in controls compared to the DSP groups. Urea and creatinine are indicators of kidney function. They were reduced with DSP compared to the control, but the results were not significant, except for urea, which was significantly lower in DSP3 compared to DSP1. Some differences were observed for liver enzymes. The consumption of DSP was associated with a significant decrease in the levels of both AST and GGT compared to the control group in a dose-dependent manner. A similar trend was observed for ALT, which was significant only in DSP1 and DSP3 compared to the control.

\section{Antioxidant status biomarkers}

The blood levels of different oxidative status biomarkers are presented in Table 5. Vitamin $\mathrm{C}$ and vitamin $\mathrm{E}$ were both increased with DSP compared to the control, but it was not significant. ABTS was significantly reduced in DSP2 and DSP3 compared to the control. Table 6 shows the levels of different biomarkers of oxidative status in the liver, muscle, heart and brain. In the liver, both vitamin $C$ and vitamin $\mathrm{E}$ were increased with DSP, but it was not significant. In contrast, GSH was significantly increased with DSP, especially in DSP3, compared to the control. In muscle, both vitamin $\mathrm{C}$ and vitamin $\mathrm{E}$ tended to increase compared to the control, but it was not significant. GSH increased with DSP and the increase was significantly different from the control with all three doses of DSP. In the heart, a significant difference was only observed for GSH, which was higher with DSP. In the brain, all the biomarkers measured did not change with DSP.

\section{Oxidative damage biomarkers}

The level of protein-bound carbonyls and MDA, biomarkers of protein and lipid oxidative damage, respectively, are shown in (Fig. 1). Protein-bound carbonyls were reduced only in muscle and significantly only in DSP1 compared with control. In serum and other organs, it tended to decrease with DSP without statistical significance.

Table 4: Weight and biochemical parameters in the control and date seed groups

\begin{tabular}{lcccc} 
& Control & DSP1 & DSP2 & DSP3 \\
\hline Growth rate (g/day) & $2.56 \pm 0.18$ & $2.84 \pm 0.14$ & $3.00 \pm 0.19$ & $3.02 \pm 0.11$ \\
Blood glucose (mmol/L) & $7.74 \pm 0.79$ & $7.82 \pm 0.59$ & $9.62 \pm 0.64$ & $9.58 \pm 0.42$ \\
Blood cholesterol (mmol/L) & $1.78 \pm 0.05$ & $1.60 \pm 0.11$ & $1.61 \pm 0.12$ & $1.53 \pm 0.11$ \\
Blood HDL-C (mmol/L/) & $1.09 \pm 0.06$ & $1.11 \pm 0.69$ & $1.06 \pm 0.08$ & $0.96 \pm 0.06$ \\
Total blood protein (g/L) & $66.60 \pm 1.92$ & $64.38 \pm 1.19$ & $65.37 \pm 1.16$ & $64.30 \pm 0.82$ \\
Blood albumin (g/L) & $41.38 \pm 0.99$ & $40.53 \pm 0.35$ & $40.83 \pm 0.63$ & $41.63 \pm 0.60$ \\
CK (IU/L) & $11701.25 \pm 846.36$ & $3881.17 \pm 1367.47^{\mathrm{a}}$ & $2103.20 \pm 345.90^{\mathrm{a}}$ & $3875.90 \pm 467.51^{\mathrm{a}}$ \\
Urea (mmol/L) & $4.96 \pm 0.24$ & $5.25 \pm 0.23$ & $5.09 \pm 0.25$ & $4.23 \pm 0.25^{\mathrm{b}}$ \\
Creatinine (mmol/L) & $35.58 \pm 1.05$ & $32.06 \pm 2.82$ & $30.76 \pm 3.03$ & $26.31 \pm 1.56$ \\
ALT (IU/L) & $62.60 \pm 10.67$ & $36.30 \pm 4.46^{\mathrm{a}}$ & $37.00 \pm 6.65$ & $37.00 \pm 4.77^{\mathrm{a}}$ \\
ALP (IU/L) & $97.05 \pm 7.21$ & $89.37 \pm 5.60$ & $89.64 \pm 12.13$ & $95.14 \pm 5.85$ \\
AST (IU/L) & $337.60 \pm 41.38$ & $201.00 \pm 40.16^{\mathrm{a}}$ & $170.75 \pm 20.95^{\mathrm{a}}$ & $149.60 \pm 9.24^{\mathrm{a}}$ \\
GGT (IU/L) & $5.75 \pm 1.25$ & $1.50 \pm 0.22^{\mathrm{a}}$ & $1.25 \pm 0.16^{\mathrm{a}}$ & $1.20 \pm 0.13^{\mathrm{a}}$ \\
\hline
\end{tabular}

a: statistically significant difference with the control group, ${ }^{\text {b: }}$ statistically significant difference with the DSP1 group, ${ }^{c}$ : statistically significant difference with the DSP2 group 
Al-Meqbaali, et al.: The antioxidant activity of date seed

Table 5: Biomarkers of the antioxidant status in the blood of the control and date seed groups

\begin{tabular}{lcccc}
\hline & Control & DSP1 & DSP2 & DSP3 \\
\hline Vitamin C $(\mu \mathrm{g} / \mathrm{ml})$ & $0.05 \pm 0.01$ & $0.04 \pm 0.00$ & $0.05 \pm 0.01$ & $0.08 \pm 0.04$ \\
Vitamin $\mathrm{E}(\mu \mathrm{g} / \mathrm{ml})$ & $2.01 \pm 0.32$ & $2.74 \pm 0.20$ & $2.64 \pm 0.34$ & $3.00 \pm 0.37$ \\
ABTS & $75.927 \pm 0.75$ & $73.25 \pm 0.48$ & $72.86 \pm 0.76^{\mathrm{a}}$ & $73.03 \pm 0.61^{\mathrm{a}}$ \\
\hline
\end{tabular}

a: statistically significant difference with the control group, ${ }^{\text {b: }}$ statistically significant difference with the DSP1 group, c: statistically significant difference with the DSP2 group

Table 6: Biomarkers of the oxidative status in organs of control and date seed groups

\begin{tabular}{|c|c|c|c|c|}
\hline & Control & DSP1 & DSP2 & DSP3 \\
\hline \multicolumn{5}{|l|}{ Liver } \\
\hline Vitamin C $(\mu \mathrm{g} / \mathrm{g})$ & $0.30 \pm 0.026$ & $0.25 \pm 0.06$ & $0.49 \pm 0.10$ & $0.65 \pm 0.16$ \\
\hline Vitamin E $(\mu \mathrm{g} / \mathrm{g})$ & $23.94 \pm 2.67$ & $41.36 \pm 8.99$ & $49.06 \pm 4.80$ & $36.01 \pm 3.72$ \\
\hline GSH $(\mu \mathrm{g} / \mathrm{g})$ & $568.80 \pm 5.71$ & $589.89 \pm 13.60$ & $572.91 \pm 9.78$ & $631.46 \pm 16.18^{\mathrm{a}, \mathrm{c}}$ \\
\hline \multicolumn{5}{|l|}{ Muscle } \\
\hline Vitamin C $(\mu \mathrm{g} / \mathrm{g})$ & $8.74 \pm 1.02$ & $10.91 \pm 1.63$ & $10.08 \pm 0.36$ & $9.31 \pm 0.76$ \\
\hline Vitamin E $(\mu \mathrm{g} / \mathrm{g})$ & $5.52 \pm 0.73$ & $4.72 \pm 0.71$ & $6.67 \pm 0.40$ & $6.50 \pm 0.37$ \\
\hline GSH (nmol/g) & $159.91 \pm 18.14$ & $258.86 \pm 17.15^{a}$ & $293.25 \pm 16.23^{a}$ & $312.02 \pm 8.70^{a, b}$ \\
\hline \multicolumn{5}{|l|}{ Heart } \\
\hline Vitamin C $(\mu \mathrm{g} / \mathrm{g})$ & $26.20 \pm 1.34$ & $21.02 \pm 2.53$ & $24.07 \pm 1.22$ & $20.54 \pm 0.95$ \\
\hline Vitamin E $(\mu \mathrm{g} / \mathrm{g})$ & $73.13 \pm 0.08$ & $64.94 \pm 8.12$ & $72.92 \pm 0.03$ & $72.96 \pm 0.02$ \\
\hline GSH (nmol/g) & $475.98 \pm 12.04$ & $505.46 \pm 10.94$ & $490.14 \pm 10.33$ & $668.83 \pm 36.77^{a, b, c}$ \\
\hline \multicolumn{5}{|l|}{ Brain } \\
\hline Vitamin C $(\mu \mathrm{g} / \mathrm{g})$ & $63.50 \pm 3.06$ & $59.28 \pm 6.70$ & $69.50 \pm 3.27$ & $66.91 \pm 2.50$ \\
\hline GSH (nmol/g) & $487.16 \pm 20.38$ & $469.25 \pm 5.94$ & $480.33 \pm 9.01$ & $476.48 \pm 10.56$ \\
\hline
\end{tabular}

a: statistically significant difference with the control group, ${ }^{\text {b: }}$ statistically significant difference with the DSP1 group, ${ }^{\text {: }}$ statistically significant difference with the DSP2 group

In contrast, MDA was significantly reduced in the liver, muscle and brain. In the liver, MDA was decreased with DSP1 and DSP3, while in the brain and muscle, the reduction was significant in all treated groups in a dosedependent manner compared to controls.

\section{Histopathology}

Liver, muscle, heart and brain samples of control rats and rats from DSP1, DSP2 and DSP3 all showed a normal appearance (Fig. 2). No changes related to ischemia were detected. These observations confirm the absence of any changes related to the oral consumption of DSP by rats.

\section{DISCUSSION}

The main purpose of this work was to investigate the effect of DSP on the antioxidant status and oxidative damage in animals. It was highlighted that DSP was able to strengthen the defence of the antioxidant system and protect against oxidative damage. In addition, the results are in favour of a lack of toxicity associated to the consumption of DSP in rats. The main biochemical indicators were not altered by the consumption of DSP and the observation of tissues did not reveal any damage.

Interestingly, DSP was associated with the increased defence of the antioxidant system in the serum and organs, as shown by the reduction of ABTS in the serum and the increased GSH in the organs. The ABTS test is used to assess the natural compounds antioxidant activity in foods or biological systems. ABTS is generated from the reaction between potassium persulfate which is one of the oxidizing agent with the ABTS salt, producing a blue-green colour ABTS free radical. The ability of the natural compound to reduce the dark blue-green-coloured ABTS free radical to the colourless form provides evidence of the antioxidant's strength (Arnao et al., 2001).

Glutathione is a small tripeptide synthesized from amino acids in the liver. It is a vital intracellular and extracellular protective antioxidant involved in many cellular functions, such as control of the signalling process, and works as a co-factor for many detoxifying enzymes of oxidative stress and xenobiotics. Also it helps in the regeneration of some important antioxidant vitamins, including vitamin C and $\mathrm{E}$. The depletion of GSH has been reported in the aging process and in many degenerative and apoptotic conditions. Consequently, the increase of GSH strengthens the antioxidant system by enhancing the protective effect against free radicals (Zitka et al., 2012). Such an elevation was observed in our work with DSP in the liver, muscle and heart. The increase in GSH could be related to the high level of date seed polyphenols, which increase the expression of $\gamma$-glutamylcysteine synthetase, the rate limiting enzyme in the synthesis of GSH (Moskaug et al., 2005). Also, 

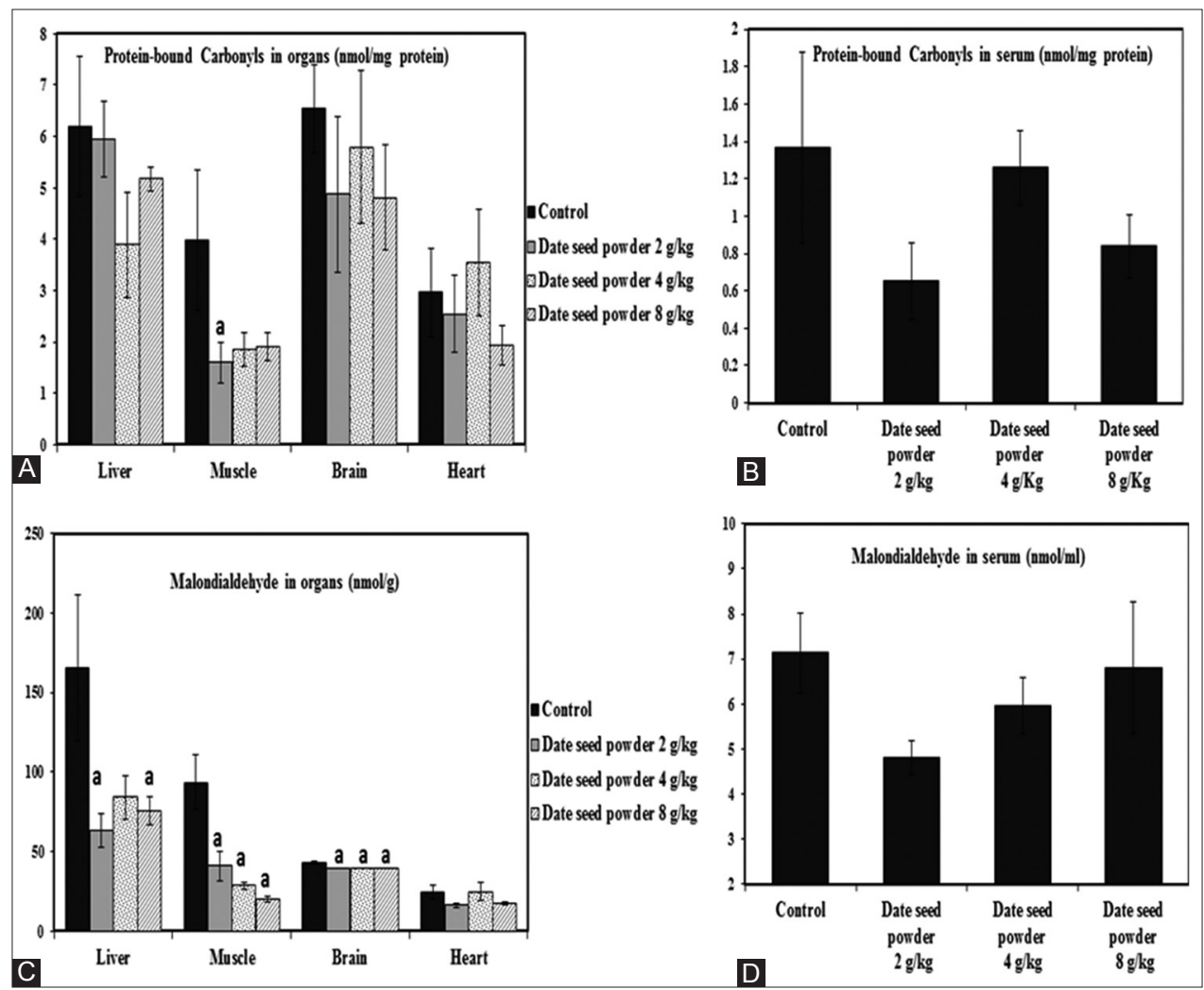

Fig 1. Effects of DSP on levels of protein-bound carbonyls in rats (A) organs, (B) serum and levels of Malondialdehyde (C) organs, (D) serum of the control and date seed groups. Means \pm s.e. are presented.

this could be explained by the fact that date seed is rich with catechins which have been shown by several studies that can upregulate anti-oxidant enzymes including GSH. In addition, many animal studies have been shown that catechins can elevate the level of glutathione in the animal's plasma and tissue. (Velayutham, et al., 2008).

Indeed, increased GSH could also be the feedback answer to an increased oxidative stress. If oxidative stress was enhanced, increased oxidative damages could also be expected. But this is not the case neither in the liver nor in muscle or heart. Protein-carbonyl bounds level remains similar to the level observed in the control groups whereas a reduction of the level of MDA is observed in these organs compared to the control group.

Surprisingly, there were no increases of GSH in the brain, even though GSH is involved in many central nervous activities as a neuromodulator and neurotransmitter and is a major antioxidant in the brain. The production of free radicals is high in the brain due to its high oxygen utilization; however, the GSH level in the brain is rather low compared to other organs. This could be related to the toxicity of the substrates used to synthesize GSH on neurons (Ballatori et al., 2009).

Vitamin C (ascorbic acid) is a water-soluble molecule that reacts directly with free radicals. Additionally, it can regenerate the reduced antioxidant form of vitamin E. Vitamin E (tocopherol) is a lipid-soluble antioxidant found in all cell membranes. It protects the cells from attack by free radicals and prevents lipid peroxidation (Machlin and Bendich, 1987). Although it was not significant, both vitamins tended to increase with DSP. A similar result for vitamin $\mathrm{E}$ was obtained by Habib and Ibrahim (Habib and Ibrahim, 2011a).

Regarding Vitamin C, the lack of significance may be explained by the fact that rats, unlike humans, can synthesize ascorbic acid in their livers due to the presence of hepatic L-gulonolactone oxidase, which is expected to encourage rats to satisfy their daily requirement for this nutrient. Additionally, rats exhibit poor ascorbic acid absorption from the diet. This means that using ascorbic acid to maintain antioxidant function would be less essential compared to the other important functions of this nutrient (Michels and Frei, 2013). Regarding vitamin E, the wide variability noted for this parameter and the sensitivity of the method cannot be ignored. Additionally, vitamin E can only be obtained from the diet. After ingestion, a rapid increase has been reported in the plasma and in the main storage organs, such as muscle, which indicates the direct regulation of the exchange between plasma and metabolically active organs. In addition, fast recycling mechanisms to maintain blood vitamin $\mathrm{E}$ in the reduced state exist (Traber and 


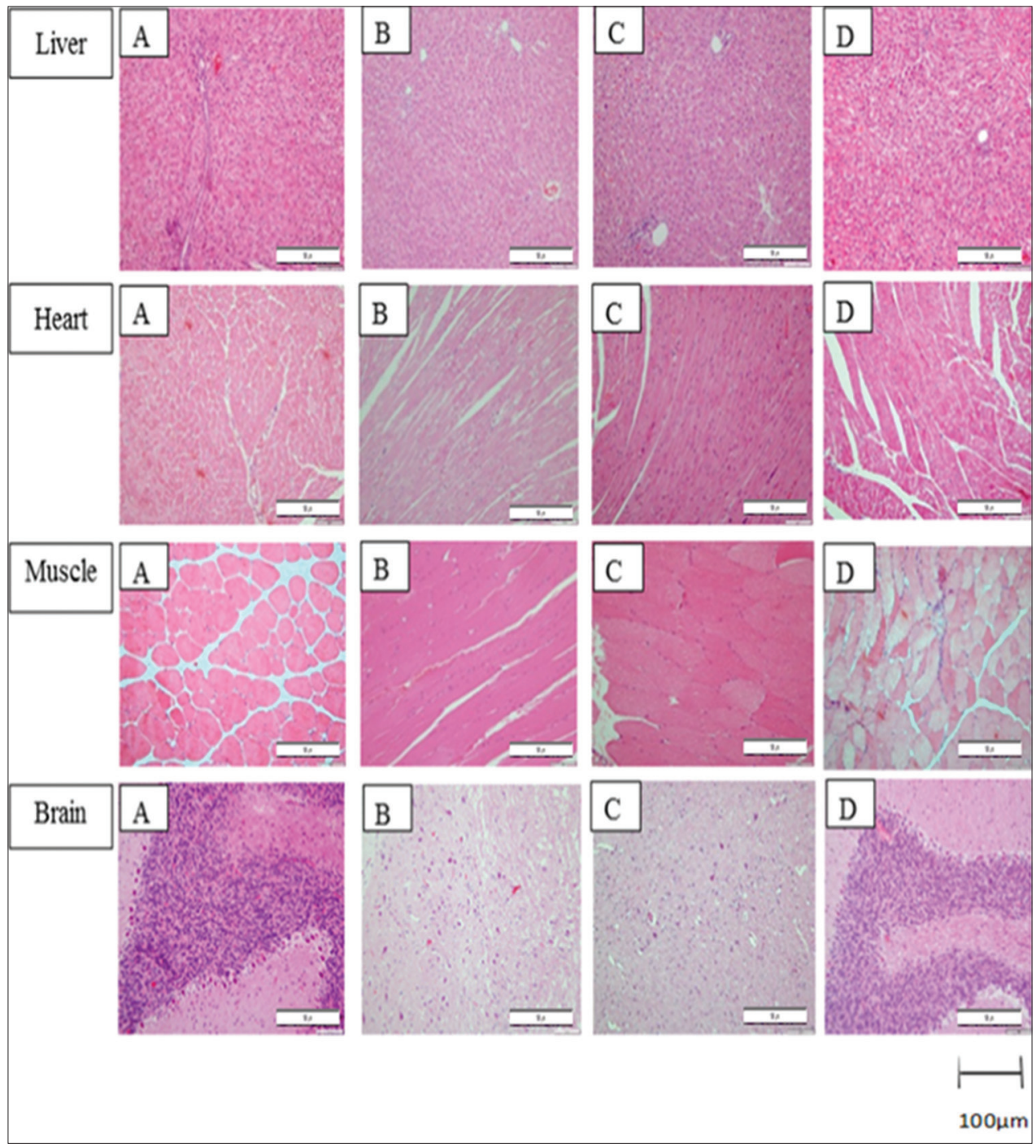

Fig 2. Histopathological observations in liver, heart, muscle and brain, Hematoxylin and eosin $\times 20$. (A) Control group, (B) date seed powder $2 \mathrm{~g} / \mathrm{kg}$, (C) date seed powder $4 \mathrm{~g} / \mathrm{kg}$, (D) date seed powder $8 \mathrm{~g} / \mathrm{kg}$.

Stevens, 2011; Packer and Fuchs, 1993). Furthermore, the trend observed for vitamin $\mathrm{E}$ level could also be related to the greater level of GSH. Indeed, GSH is known to interact with Vitamin $\mathrm{E}$ to maintain it in its reduced form (Scholz et al., 1989). This could be attributed to date seed catechins as previous studies showed that catechins can also contribute in the recycling process of vitamin $\mathrm{E}$, and thus complement the functions of glutathione (Velayutham et al., 2008).

The DSP protective effect against lipid and protein oxidative damage was highlighted. The generation of ROS can cause damage to many molecules in the body, including proteins. One of the most generally used indicators for protein oxidation products is protein-bound carbonyl. It is generated from protein oxidation either through glutamyl side chain oxidation or the $\alpha$-amidation pathway. A peptide with an $\mathrm{N}$-terminal amino acid is generated from this oxidation process and it is blocked by $\alpha$-ketoacyl derivatives. The accumulation of protein-bound carbonyls has been observed in many diseases, including diabetes, Alzheimer's disease and arthritis (Dalle-Donne et al., 2003). In the present study, protein-bound carbonyls tended to decrease with DSP in all groups, supporting a protective effect of DSP against oxidative damage to proteins. Nonetheless, the reduction was significant only in muscle with DSP at a concentration of $2 \mathrm{~g} / \mathrm{kg}$. This could be explained by the fact that skeletal muscles represent approximately $40 \%$ of the mammalian body weight, and at least $25 \%$ of the protein turnover occurs in these tissues. In addition, skeletal muscles include many other proteins that are involved in performing muscle function and produce high levels of ROS due to their high rate of metabolic activity (Fedorova et al., 2009). Therefore, the protective effect of DSP against the oxidative damage of proteins would be more strongly expressed and more intense in muscles. 
Regarding the indicators of lipid peroxidation, MDA was used in this study, as it is one of the main aldehyde that results from the lipid peroxidation and has been studied intensely in many researches. MDA which is a product of lipid hydroperoxides break down is considered to be a good biomarker of the pathologic damage linked to oxidative stress (Del Rio et al 2005). MDA was significantly reduced with all DSP concentrations in the liver, muscle and brain, while in the serum and heart, the reduction was not significant. Similar results were obtained by Habib and Ibrahim in the liver after only 30 days of consumption (Habib and Ibrahim, 2011a). The serum and heart MDA levels could be affected by the blood sampling tube, the stability of the biomarker during different storage conditions, the sensitivity and reproducibility of the method and the steps of specimen preparation. In addition, the serum antioxidant level may be affected by different factors, including homeostatic regulation and the degree of absorption (Ho et al., 2013; Wu et al. 2004; Hagfors et al., 2003; Meagher and Fitz Gerald, 2000).

Additionally, other studies were not able to illustrate the direct antioxidant effect of the biological application of polyphenols on cardiovascular health. Some foods rich in polyphenols exert beneficial effects on some biomarkers of cardiovascular health. However, there is no concrete evidence that the improvement in antioxidant biomarkers and markers of oxidative damage, such as MDA, represent a true benefit to health (Hollman et al., 2011).

Finally, the absence of change in the main biochemical parameters after consumption of DSP is suggesting that consumption of DSP would be safe in rat. Urea and creatinine, which are both nitrogenous end-products of metabolism used in screening tests for renal function, did not significantly change with DSP. Because the elevation of urea and creatinine is an indicator of renal disease, this indicates that DSP does not interfere with renal function. Additionally, intracellular enzymes, including ALT, AST, ALP, GGT and LDH, which are indicators of tissue injury, especially the liver for ALT, AST and ALP, (Al-Rasheed et al., 2015; Drent et al., 1996) were considered. An increase of these parameters has been related to hepatic, pancreatic and skeletal muscle diseases (Gowda et al., 2009). Their decrease with DSP indicates that DSP did not alter tissue functions and could improve their function through a protective effect on organs. A similar decrease was already observed in a previous study with DSP (Habib and Ibrahim, 2011a).

This effect could be due to the polyphenol content of DSP, especially phenolic compounds. Indeed, they were found to reduce the leakage of liver enzymes into the blood by providing protection against free radicals that can cause tissue damage (Eid et al., 2015; Habib and Ibrahim, 2011a; Rahman, 2007).

\section{CONCLUSIONS}

The results of this study clearly showed that DSP exerted a protective effect against oxidative stress in vivo mainly through its antioxidant potential and by strengthening the endogenous antioxidant system without altering any tissue function, as shown by analysis of the biochemical parameters and histopathology. Thus, DSP is a potential candidate to reduce the markers of oxidative damage, especially MDA, in organs. Therefore, considering the role of oxidative stress as a mechanism underlying chronic diseases, it can be concluded that DSP could contribute to prevent these diseases. Although polyphenols can be suspected to be at least in part responsible for these effects of DSP in vivo, the underlying mechanisms require further investigation.

\section{ACKNOWLEDGMENTS}

This research project received a United Arab Emirates Research Grant in 2012.

\section{Author contributions}

Mrs. Fatima Al Meqbaali wrote, the manuscript. She measured the antioxidant status biomarkers and the oxidative damage biomarkers. Also, she participated in data analysis, and interpretation. This was part of her MSc work. Dr Hosam Habib involved in project development and date seeds products preparation. Mr. Aws Othman was in charge of taking care of the animals, including weighing, feeding, cleaning and follow-up with the investigator. He participated in blood and organs collection. Mrs. Saeda Al-Marzooqi and Mrs. Alia Al-Bawardi, both did the histopathology. Mr. Javed Yasin Pathan did the biochemical analysis. Mr. Usama Souka and Mrs. Serene Hilary assisted on the antioxidant status biomarkers and the oxidative damage biomarkers analysis. Dr Suleiman was the coordinator from College of Medical \& Health sciences and let investigators use animal facilities. Prof. Wissam Ibrahim involved in project development and paper review. Dr Carine Platat was the principal investigator and brought the idea of the experiment. She arranged and coordinated the animal study, participated in data analysis and interpretation. She revised the manuscript with the first author.

\section{REFERENCES}

Al-Farsi, M. and C. Lee. 2011. Usage of date (Phoenix Dactylifera L.) seeds in human health and animal feed. Nuts and Seeds in 
Health and Disease Prevention. Academic Press, Burlington, MA. pp. 447-452.

Al-Qarawi, A. A., H. M. Mousa, B. H. Ali, H. Abdel-Rahman and S. A. El-Mougy. 2004. Protective effect of extracts from dates (Phoenix dactylifera L.) on carbon tetrachloride-induced hepatotoxicity in rats. Int. J. Appl. Res. Vet. Med. 2(3): 176-180.

Al-Rasheed, N. M., H. A. Attia, R. A. Mohamad, N. M. AlRasheed, M. A. Al-Amin and A. Al-Onazi. 2015. Aqueous date flesh or pits extract attenuates liver fibrosis via suppression of hepatic stellate cell activation and reduction of inflammatory cytokines, transforming growth factor- $\beta 1$ and angiogenic markers in carbon tetrachloride-intoxicated rats. J. Evid. Based Complement. Altern. Med. 2015: 247357.

Ali, B., A. Bashir and G. Alhadrami. 1999. Reproductive hormonal status of rats treated with date pits. Food Chem. 66(4): 437-441.

Arnao, M. B., A. Cano and M. Acosta. 2001. The hydrophilic and lipophilic contribution to total antioxidant activity. Food Chem. 73(2): 239-244.

Ballatori, N., S. M. Krance, S. Notenboom, S. Shi, K. Tieu and C. L. Hammond. 2009. Glutathione dysregulation and the etiology and progression of human diseases. Biol. Chem. 390(3): 191-214.

Beal, M. F. 2002. Oxidatively modified proteins in aging and disease 1, 2. Free Radic. Biol. 32(9): 797-803.

Berlett, B. S. and E. R. Stadtman. 1997. Protein oxidation in aging, disease, and oxidative stress. J. Biol. Chem. 272(33): 20313-20316.

Bouayed, J. and T. Bohn. 2010. Exogenous antioxidants-doubleedged swords in cellular redox state: Health beneficial effects at physiologic doses versus deleterious effects at high doses. Oxid. Med. Cell. Longev. 3(4): 228-237.

Chevion, M., E. Berenshtein and E. Stadtman. 2000. Human studies related to protein oxidation: Protein carbonyl content as a marker of damage. Free Radic. Res. 33: S99-S108.

Dalle-Donne, I., R. Rossi, D. Giustarini, A. Milzani and R. Colombo. 2003. Protein carbonyl groups as biomarkers of oxidative stress. Clin. Chim. Acta. 329(1): 23-38.

Del Rio, D., A. J. Stewart and N. Pellegrini. 2005. A review of recent studies on malondialdehyde as toxic molecule and biological marker of oxidative stress. Nutr. Metab. Cardiovasc. Dis. 15(4): 316-328.

Drent, M., N. Cobben, R. Henderson, E. Wouters and M. van DieijenVisser. 1996. Usefulness of lactate dehydrogenase and its isoenzymes as indicators of lung damage or inflammation. Eur. Respir. J. 9(8): 1736-1742.

Eid, H. H., R. M. Labib, N. S. A. Hamid, M. A. Hamed and S. A. Ross. 2015. Hepatoprotective and antioxidant polyphenols from a standardized methanolic extract of the leaves of Liquidambar styraciflua L. Bull. Fac. Pharm. Cairo Univ. 53(2): 117-127.

Fedorova, M., N. Kuleva and R. Hoffmann. 2009. Reversible and irreversible modifications of skeletal muscle proteins in a rat model of acute oxidative stress. BBA Mol. Basis. Dis. 1792(12): 1185-1193.

Gowda, S., P. B. Desai, V. V. Hull, A. A. K. Math, S. N. Vernekar and S. S. Kulkarni. 2009. A review on laboratory liver function tests. Pan Afr. J. 3: 17.

Habib, H. M. and W. H. Ibrahim 2011a. Effect of date seeds on oxidative damage and antioxidant status in vivo. J. Sci. Food Agric. 91(9): 1674-1679

Habib, H. M. and W. H. Ibrahim. 2011b. Nutritional quality of 18 date fruit varieties. Int J Food Sci. Nutr. 62(5): 544-551.

Habib, H. M., C. Platat, E. Meudec, V. Cheynier and W. H. Ibrahim. 2014. Polyphenolic compounds in date fruit seed (Phoenix dactylifera): Characterisation and quantification by using UPLC DAD-ESI-MS. J. Sci. Food Agric. 94(6): 1084-1089.

Hagfors, L., P. Leanderson, L. Sköldstam, J. Andersson and G. Johansson. 2003. Antioxidant intake, plasma antioxidants and oxidative stress in a randomized, controlled, parallel, mediterranean dietary intervention study on patients with rheumatoid arthritis. Nutr. J. 2(1): 1-11.

Hamada, J., I. Hashim and F. Sharif. 2002. Preliminary analysis and potential uses of date pits in foods. Food Chem. 76(2): 135-137.

Hatam, L. J. and H. J. Kayden. 1979. A high-performance liquid chromatographic method for the determination of tocopherol in plasma and cellular elements of the blood. J. Lipid Res. 20(5) 639-645.

Ho, E., K. K. Galougahi, C. C. Liu, R. Bhindi and G. A. Figtree. 2013. Biological markers of oxidative stress: Applications to cardiovascular research and practice. Redox Biol. 1(1): 483-491.

Hollman, P. C., A. Cassidy, B. Comte, M. Heinonen, M. Richelle, E. Richling, M. Serafini, A. Scalbert, H. Sies and S. Vidry. 2011. The biological relevance of direct antioxidant effects of polyphenols for cardiovascular health in humans is not established. J. Nutr. 141(5): 989S-1009S.

Jeong, W. S. and A. N. T. Kong. 2004. Biological properties of monomeric and polymeric catechins: Green tea catechins and procyanidins. Pharm. Biol. 42 Suppl 1: 84-93.

Khansari, N., Y. Shakiba and M. Mahmoudi. 2009. Chronic inflammation and oxidative stress as a major cause of agerelated diseases and cancer. Recent Pat. Antiinfect. Drug Discov. 3(1): 73-80.

Levine, R. L., D. Garland, C. N. Oliver, A. Amici, I. Climent, A. G. Lenz, B. W. Ahn, S. Shaltiel and E. R. Stadtman. 1990. Determination of carbonyl content in oxidatively modified proteins. Meth. Enzymol. 186: 464-478.

Li, X. Y. and C. K. Chow. 1994. An improved method for the measurement of malondialdehyde in biological samples. Lipids. 29(1): 73-75.

Lowry, O. H., N. J. Rosebrough, A. L. Farr and R. J. Randall. 1951. Protein measurement with the Folin phenol reagent. J. Biol. Chem. 193(1): 265-275.

Machlin, L. J. and A. Bendich. 1987. Free radical tissue damage: Protective role of antioxidant nutrients. FASEB J. 1(6): 441-445.

Mayne, S. T. 2003. Antioxidant nutrients and chronic disease: Use of biomarkers of exposure and oxidative stress status in epidemiologic research. J. Nutr. 133(3): 933S-940S.

Meagher, E. A. and G. A. FitzGerald. 2000. Indices of lipid peroxidation in vivo: Strengths and limitations. Free Radic. Biol. Med. 28(12): $1745-1750$.

Michels, A. J. and B. Frei. 2013. Myths, artifacts, and fatal flaws: Identifying limitations and opportunities in Vitamin C research. Nutrients. 5(12): 5161-5192.

Moskaug, J. Ø., H. Carlsen, M. C. Myhrstad and R. Blomhoff. 2005. Polyphenols and glutathione synthesis regulation. Am. J. Clin. Nutr. 81(1): 277S-283S.

NRC. 1985. Guide for the Care and Use of Laboratory Animals. National Institute of Health, Washington, DC.

Omaye, S. T., J. Tumball and H. E. Sauberlich. 1979. Selected methods for the determination of ascorbic acid in animal cells, tissues and fluids. Meth. Enzymol. 62: 3-11.

Packer, L. and J. Fuchs. 1993. Vitamin E in Health and Disease. Marcel Dekker Inc., New York,. p. 179.

Pandey, K. B. and S. I. Rizvi. 2009. Plant polyphenols as dietary antioxidants in human health and disease. Oxid. Med. Cell. Longev. 2(5): 270-278. 
Platat, C., H. M. Habib, F. D. A. Maqbali, N. N. Jaber and W. H. Ibrahim. 2014. Identification of date seeds varieties patterns to optimize nutritional benefits of date seeds. J. Nutr. Food Sci. 8: 8.

Rahman, I., S. K. Biswas and P. A. Kirkham. 2006. Regulation of inflammation and redox signaling by dietary polyphenols. Biochem. Pharmacol. 72(11): 1439-1452.

Rahman, K. 2007. Studies on free radicals, antioxidants, and cofactors. Clin. Interv. Aging. 2(2): 219-236.

Re, R., N. Pellegrini, A. Proteggente, A. Pannala, M. Yang and C. Rice-Evans. 1999. Antioxidant activity applying an improved ABTS radical cation decolorization assay. Free Radic. Biol. 26(9): 1231-1237.

Scholz, R., K. Graham, E. Gumpricht and C. Reddy. 1989. Mechanism of interaction of Vitamin $E$ and glutathione in the protection against membrane lipid peroxidation. Ann. N. Y. Acad. Sci. 570(1): 514-517.

Sedlak, J. and R. H. Lindsay. 1968. Estimation of total, protein-bound, and nonprotein sulfhydryl groups in tissue with Ellman's reagent. Anal. Biochem. 25: 192-205.

Shams-Ardekani, M., M. Khanavi, M. Hajimahmoodi, M. Jahangiri and A. Hadjiakhoondi. 2010. Comparison of antioxidant activity and total phenol contents of some date seed varieties from Iran. Iran J. Pharm. Res. 9(2): 141-146.

Simos, Y. V., I. I. Verginadis, I. K. Toliopoulos, A. P. Velalopoulou, I. V. Karagounis, S. C. Karkabounas and A. M. Evangelou. 2012. Effects of catechin and epicatechin on superoxide dismutase and glutathione peroxidase activity, in vivo. Redox Rep. 17(5): 181-186.
Traber, M. G. and J. F. Stevens. 2011. Vitamins C and E: Beneficial effects from a mechanistic perspective. Free Radic. Biol. Med. 51(5): 1000-1013.

Uttara, B., A. V. Singh, P. Zamboni and R. Mahajan. 2009. Oxidative stress and neurodegenerative diseases: A review of upstream and downstream antioxidant therapeutic options. Curr. Neuropharmacol. 7(1): 65-74.

Velayutham, P., A. Babu and D. Liu. 2008. Green tea catechins and cardiovascular health: An update. Curr. Med. Chem. 15(18): 1840-1850.

World Health Organization. 2003. The World Health Report 2003: Shaping the Future. WHO Press, Geneva, Switzerland. Available from: http://www.who.int/whr/2003/en. [Last accessed on 2016 Sep].

World Health Organization. 2014. Noncommunicable Diseases Country Profiles. WHO Press, Geneva, Switzerland. Available from: http://www.who.int/nmh/publications/ncd-profiles-2014/en. [Last accessed on 2016 Sep].

Wu, T., N. Rifai, L. J. Roberts, W. C. Willett and E. B. Rimm. 2004. Stability of measurements of biomarkers of oxidative stress in blood over 36 hours. Cancer Epidemiol. Biomarkers Prev. 13(8): 1399-1402.

Zitka, O., S. Skalickova, J. Gumulec, M. Masarik, V. Adam, J. Hubalek, L. Trnkova, J. Kruseova, T. Eckschlager and R. Kizek. 2012. Redox status expressed as GSH: GSSG ratio as a marker for oxidative stress in paediatric tumour patients. Oncol. Lett. 4(6): 1247-1253. 